\title{
A Schiff Base Fluorescence Enhancement Probe for Fe(III) and Its Sensing Applications in Cancer Cells
}

\author{
Na Hee Kim ${ }^{1}$, Junho Lee ${ }^{2}$, Sungnam Park ${ }^{2}$, Junyang Jung ${ }^{1,3, *}$ and Dokyoung Kim ${ }^{1,3,4,5, * \mathbb{C}}$ \\ 1 Department of Biomedical Science, Graduate School, Kyung Hee University, Seoul 02447, Korea; \\ pionaheek@gmail.com \\ 2 Department of Chemistry, Korea University, Seoul 02841, Korea; pplkjh269@gmail.com (J.L.); \\ spark8@korea.ac.kr (S.P.) \\ 3 Department of Anatomy and Neurobiology, College of Medicine, Kyung Hee University, Seoul 02447, Korea \\ 4 Center for Converging Humanities, Korea University, Seoul 02841, Korea \\ 5 Medical Research Center for Bioreaction to Reactive Oxygen Species and Biomedical Science Institute, \\ School of Medicine, Graduate School, Kyung Hee University, Seoul 02841, Korea \\ * $\quad$ Correspondence: jjung@khu.ac.kr (J.J.); dkim@khu.ac.kr (D.K.); Tel.: +82-02-961-0297 (D.K.)
}

Received: 23 April 2019; Accepted: 30 May 2019; Published: 31 May 2019

\begin{abstract}
We report a new Schiff base fluorescent probe which senses ferric ion, $\mathrm{Fe}(\mathrm{III})$, with a significant fluorescence enhancement response. The probe showed high sensitivity $(0.8 \mathrm{ppb})$, and fast response time $(<10 \mathrm{~s})$ of $\mathrm{Fe}(\mathrm{III})$ in aqueous media. In addition, the probe showed the ability to sense $\mathrm{Fe}(\mathrm{III})$ in a HeLa cancer cell line, with very low cytotoxicity. As a new bio-imaging probe for Fe(III), it gave bright fluorescent images in confocal laser scanning microscopy (CLSM).
\end{abstract}

Keywords: fluorescent probe; Schiff base probe; iron ion sensing; D-A type fluorophore; bioimaging

\section{Introduction}

Efficient detection of biologically important metal ions and the development of new fluorescent probes capable of this sensing is an important research topic in biology, chemical biology, environmental science, and medicine [1-3]. Iron ( $\mathrm{Fe})$ is an essential element among biologically important metal ions and plays crucial roles in blood production, heme synthesis, conversion of food to energy, immune cells proliferation and maturation, and normal cognitive function maintenance [4,5]. A high or low concentration of iron may induce disorders like Alzheimer's disease (AD), Parkinson's disease (PD), chronic kidney disease (CKD), and others [6,7]. Generally, iron exists in oxidation states between -2 and +7 , but the most common are ferrous $\left(\mathrm{Fe}^{2+}, \mathrm{Fe}(\mathrm{II})\right)$ and ferric $\left(\mathrm{Fe}^{3+}, \mathrm{Fe}(\mathrm{III})\right)$ states [8]. In order to understand the active mechanism between the biological functions of ferrous and ferric, a detailed observation on each iron state is very important. For this reason, the development of a selective and sensitive molecular sensing system and fluorescent probe for each iron state has been highlighted.

To date, many fluorescent probes for Fe(III) have been reported (Figure S1, Supplementary Information) [9], and their approaches can be categorized into two; (i) selective binding between Fe(III) and ligand, and (ii) Fe(III)-induced chemical reactions. In the first approach, an imine-containing Schiff base fluorescent probe showed $\mathrm{Fe}(\mathrm{III})$-sensing ability via monomer binding or excimer formation of blue-emitting dyes. However, low selectivity and interference from other heavy metal ions such as aluminum ions, $\mathrm{Al}(\mathrm{III})$, was considered disadvantageous (Figure S1). In some cases, the fluorescent emission at shorter wavelengths $\left(\lambda_{\mathrm{emi}}=400-500 \mathrm{~nm}\right)$ or the turn-off property in Fe(III)-sensing, limits their usage in biological studies. Although such Schiff base fluorescence probes have drawbacks, they still have merits such as high sensitivity, fast response, reversibility, and have no side product generation [10]. The design of new Schiff moiety and fluorescent probes that fulfill $\mathrm{Fe}(\mathrm{III})$ sensing is very 
challenging due to strong fluorescence quenching effects of Fe(III) and difficult for the discrimination of $\mathrm{Fe}(\mathrm{II})$. In this study, we developed a new Schiff base fluorescent probe for Fe(III) sensing with fluorescence enhancement, and its bioimaging applications.

\section{Materials and Methods}

\subsection{Materials}

The chemical reagents were purchased from Aldrich (St. Louis, MO, USA), TCI (Tokyo, Japan), Alfa Aesar (Ward Hill, MA, USA), Deajung (Seoul, Korea), and Samchun (Seoul, Korea). Metal ions and amino acid (Aldrich, Alfa Aesar, Daejung, >97\% purity): $\mathrm{FeCl}_{3}, \mathrm{Fe}\left(\mathrm{NO}_{3}\right)_{3}, \mathrm{FeCl}_{2}, \mathrm{HgCl}_{2}, \mathrm{AgCl}$, $\mathrm{CdCl}_{2}, \mathrm{NiCl}_{2}, \mathrm{CuCl}_{2}, \mathrm{PdCl}_{2}, \mathrm{ZnCl}_{2},\left(\mathrm{C}_{2} \mathrm{H}_{5}\right)_{3} \mathrm{PAuCl}, \mathrm{KCl}, \mathrm{CaCl}_{2}, \mathrm{NaCl}, \mathrm{MgCl}_{2}$, L-Cysteine, L-Glutamine, L-Lysine, Lysozyme. Hydrogen peroxide was purchased from TCI ( $35 \%$ in water, TCI, Tokyo, Japan). Commercially available reagents and anhydrous solvents were used without further purification. Chemical reactions were performed under argon atmosphere. Thin-layer chromatography (TLC) was performed using pre-coated silica gel 60F-254 glass plates (Merck KGaA, Darmstadt, Germany).

\subsection{UV/Vis Absorption and Emission Measurement}

UV/Vis absorption spectra were obtained using spectrophotometer (Agilent Technologies Cary 8454, Santa Clara, CA, USA). Fluorescence spectrum were recorded on a spectro-fluorophotometer (SHIMADZU CORP. RF-6000, Kyoto, Japan) with a $1 \mathrm{~cm}$ standard quartz cell (internal volume of $1 \mathrm{~mL}, 108-000-10-40(10 \mathrm{~mm}), 108-\mathrm{F}-10-40(10 \times 4 \mathrm{~mm})$; Hellma Analytics, Müllheim, Germany). The absorption and fluorescence spectrum were recorded at $10 \mu \mathrm{M}$ concentration of FeP-1 at $25^{\circ} \mathrm{C}$.

\subsection{NMR and Mass Analysis}

${ }^{1} \mathrm{H}$ NMR and ${ }^{13} \mathrm{C}$ NMR spectra were measured with a Bruker AVANCE III $400 \mathrm{MHz}$ (Bruker, Billerica, MA, USA). In the NMR spectra, the chemical shifts $(\delta)$ are reported in ppm, multiplicity are indicated by s (singlet), $\mathrm{d}$ (doublet), $\mathrm{t}$ (triplet), dd (double of doublets), and $\mathrm{m}$ (multiplet). Spectra were referenced to residual DMSO (2.50 ppm) in ${ }^{1} \mathrm{H}$ NMR. High-resolution mass spectra were recorded on a JEOL JMS-700 spectrometer (JEOL, Tokyo, Japan) at the Korea Basic Science Center, Kyung-pook National University, and the values are reported in units of mass to charge $(\mathrm{m} / \mathrm{z})$.

\subsection{Quantum Chemical Calculations}

All calculations were carried out using the density functional theory (DFT) method at the APFD level with the $6-31+G(d, p)$ basis set as implemented in the Gaussian 16 package. The optimized structures and frontier orbitals (highest occupied molecular orbital; HOMO and lowest unoccupied molecular orbital; LUMO) of FeP-1 and FeP-1 + Fe(III) were obtained using the DFT method. The integral equation formalism polarizable continuum (IEF-PCM) model was used for solvation.

\subsection{Cell Culture and CLSM Imaging of Cells}

HeLa cell line was obtained from the Korean Cell Line Bank. Cells were cultured in Dulbecco's modified Eagle's media (Hyclone, Logan, UT, USA) supplemented with $10 \%$ fetal bovine serum (Hyclone) and $1 \%$ penicillin-streptomycin (Gibco). Cultures were incubated at $37^{\circ} \mathrm{C}$ in humidified air containing $5 \% \mathrm{CO}_{2}$. Approximately $5 \times 10^{4}$ cells were seeded on $35 \mathrm{~mm}$ glass bottom confocal dishes (SPL Life Science, Gyeonggi-do, Korea) and incubated for $24 \mathrm{~h}$. At the $80 \%$ confluency, the experiment was carried out. (i) FeP-1: FeP-1 $(50 \mu \mathrm{M})$ was treated to cells for $2 \mathrm{~h}$. (ii) $\mathrm{Fe}(\mathrm{III})$ : cells with the Fe(III) $(50 \mu \mathrm{M})$ incubated for $2 \mathrm{~h}$. (iii) FeP-1 + Fe(III): cells pretreated the FeP-1 $(50 \mu \mathrm{M})$ for $2 \mathrm{~h}$ and then incubated with $\mathrm{Fe}$ (III) $(50 \mu \mathrm{M})$ for $2 \mathrm{~h}$ at $37^{\circ} \mathrm{C}$ in $5 \% \mathrm{CO}_{2}$. Fluorescence images were visualized by a confocal laser scanning microscope (CLSM, LSM-800, Carl Zeiss, Germany). Excitation wavelength: $450 \mathrm{~nm}$. Fluorescence detection channel; $455-600 \mathrm{~nm}$. 


\subsection{Cell Viability Assay}

Approximately $1 \times 10^{5}$ cells were seeded on a 96-well transparent bottom plate (SPL Life Science, Gyeonggi-do, Korea) and incubated for $24 \mathrm{~h}$. After incubation, the cells were treated with DMSO as a control and FeP-1 $(0,1,3,10,30,50$ and $100 \mu \mathrm{M})$ for $24 \mathrm{~h}$. The cell viability was analyzed by Vybrant®MTT Cell Proliferation Assay Kit (ThermoFisher, Waltham, MA, USA) following manufacturer's instructions. The absorbance level was analyzed at $550 \mathrm{~nm}$ by microplate reader (Multiskan $^{\mathrm{TM}}$ FC Microplate Photometer, ThermoFisher, Waltham, MA, USA). The culture medium was used as a control set.

\section{Results and Discussion}

We recently focused on the development of a naphthalene-based donor (D)-acceptor (A) type fluorescent platform in order to monitor biologically important targets, such as enzyme activity, cell organelles, metal ions, and carcinogens [11-14]. During this research process, we found a new Schiff base fluorescent probe, FeP-1, that can sense Fe(III) with significant fluorescence enhancements (Figure 1a). This is the first report of a Schiff-type ligand on the D-A type fluorophore for Fe(III). We clearly identified the synthesis of the probe, sensing properties, and DFT calculations. To verify the application to biological studies, we demonstrated the tracking of endogenous as well as exogenous $\mathrm{Fe}(\mathrm{III})$ in HeLa cells via fluorescence imaging. Another key advantage was a low level of cytotoxicity.

The Schiff base probe, FeP-1, was prepared by one step synthesis, condensing 6-(dimethylamino)-3-hydroxy-2-naphth-aldehyde with 2-(methylthio)-aniline, and a catalytic amount of acetic acid in refluxing dichloromethane, which produced an ocher-colored solid at $69 \%$ yield (Scheme S1, Supplementary Information). The product was characterized by ${ }^{1} \mathrm{H} /{ }^{13} \mathrm{C}$ NMR and high-resolution mass spectrometry (Supplementary Data).

We discovered that the excited state intramolecular proton transfer (ESIPT) caused the fluorescence quenching of FeP-1, and the coordination with Fe(III) may suppress this pathway (Figure S2) [15-17]. Thus, the coordination of Fe(III) in the naphthol-imine-thiomethyl pocket of FeP-1 would accompany both absorption and emission enhancements. This scenario was demonstrated through in vitro experiments as well as computational calculation, enabling us to sense $\mathrm{Fe}$ (III) as a form of fluorescence enhancement.

A solution of FeP-1 in aqueous media ( $\left.\mathrm{DI} \mathrm{H}_{2} \mathrm{O}: \mathrm{EtOH}=6: 4, v / v\right)$ exhibited weak fluorescence at an emission maximum of $550 \mathrm{~nm}$. However, after being treated with $\mathrm{Fe}(\mathrm{III})$, it showed significant fluorescence enhancement (Figure 1b,c). In the different ethanol fractions (30-100\%), the fluorescence intensity of FeP-1 itself became higher as ethanol fraction increased, and the fluorescence enhancement factor toward Fe(III) also increased ( $>2$ fold) (Figure S3). Time-course fluorescence changes for the mixture of FeP-1 and Fe(III) was monitored in the given solution at $25{ }^{\circ} \mathrm{C}$ under excitation at the maximum absorption wavelength, $397 \mathrm{~nm}$. As shown in Figure 1d, when Fe(III) was treated in a solution of FeP-1, a fluorescence enhancement was rapidly observed within $10 \mathrm{~s}$, and it was saturated. A good linear relationship between the fluorescence intensity of FeP-1 $(10 \mu \mathrm{M})$ and Fe(III) was observed for a wide range of $\mathrm{Fe}(\mathrm{III})$ concentration $(0-200 \mu \mathrm{M})$ (Figure S4), but an excessive amount of Fe(III) rather quenched the fluorescence. This data represent that the complex formation between FeP-1 and Fe(III) is not corresponded to 1:1 binding. In the low concentration range of Fe(III), FeP-1 displayed a high sensitivity; detection limit for $0.8 \mathrm{ppb}$ (Figure 1e). Only Fe(III) enhanced the significant fluorescence of FeP-1, and other metal ions or enzymes showed a little responses (Figure 1f, Figure S5). A slight interference from some of metal ions and biomolecules was observed, but the signal enhancement mainly observed in the presence of Fe(III) (threshold at 32 a.u. in Figure 1f). A slightly decreased signal of FeP-1 in the mixture of Fe(III) and metal ions (i.e., $\mathrm{Pd}(\mathrm{II}), \mathrm{Zn}(\mathrm{II}), \mathrm{Au}(\mathrm{III}), \mathrm{Ca}(\mathrm{II}), \mathrm{Na}$ (I), $\mathrm{Mg}(\mathrm{II})$ ) was observed. Currently, we are focused on this phenomenon to understand the reason, and the information will be published somewhere. In addition, a decreased fluorescence signal of FeP-1 with $\mathrm{Fe}(\mathrm{III})$ in the presence of lysozyme was also monitored, and the result might be caused from the aggregation factor of lysozyme in the given sensing media. 
(a)
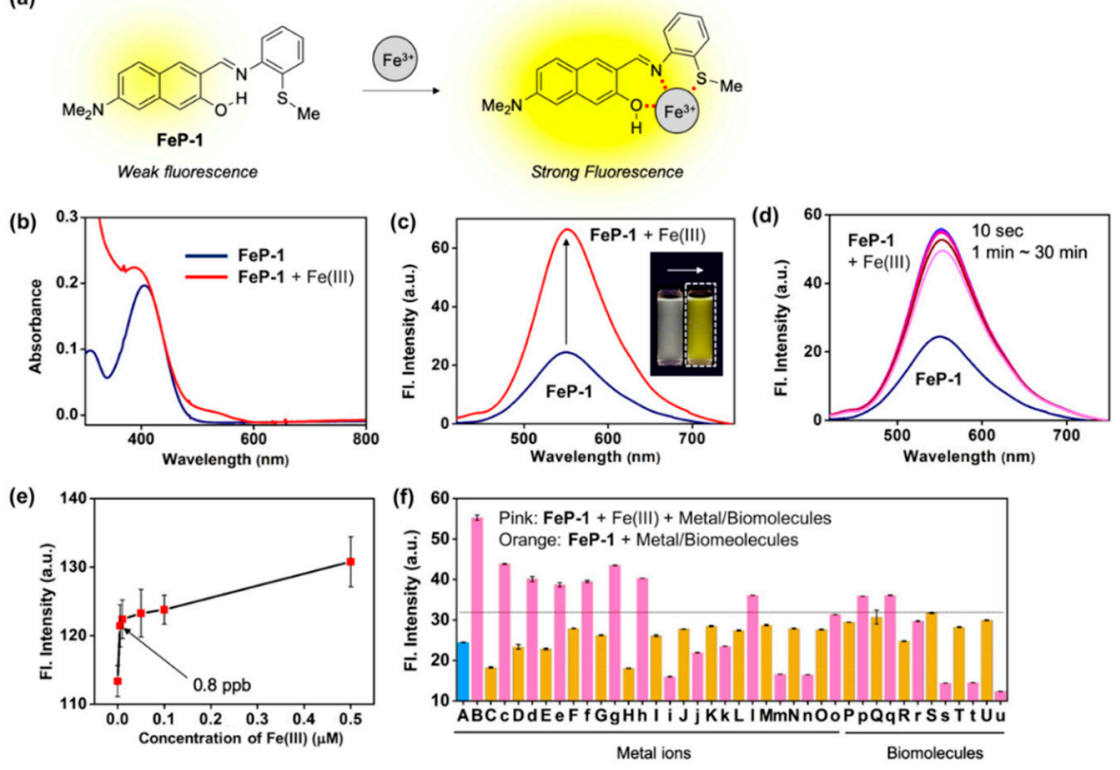

Figure 1. (a) Proposed sensing mechanism between Fe(III) and Schiff base fluorescence enhancement probe, FeP-1. (b,c) Absorption and emission spectra of FeP-1 (10 $\mu \mathrm{M})$ after addition of Fe(III) (20 eq). Inset photo: color change of the probe under UV light $(365 \mathrm{~nm})$ after addition of the Fe(III) (20 eq). Each spectrum was acquired in ethanol-water solution (EtOH:DI $\left.\mathrm{H}_{2} \mathrm{O}=4: 6, v / v\right)$ after $1 \mathrm{~min}$ at $25^{\circ} \mathrm{C}$ under excitation at $397 \mathrm{~nm}$. (d) Time-dependent fluorescence spectra of FeP-1 (10 $\mu \mathrm{M})$ with Fe(III) (20 eq). Emission spectrum was measured at $10 \mathrm{~s}, 1$, 3, 5, 10, 20, $30 \mathrm{~min}$ after mixing together. (e) A plot of fluorescence intensity (peak height at $550 \mathrm{~nm})$ of FeP-1 $(0.5 \mu \mathrm{M})$ after addition of Fe(III) $(0-0.5 \mu \mathrm{M})$. Mean and standard deviations was calculated in triplicate. (f) Fluorescence intensity plot (peak height at $550 \mathrm{~nm})$ of FeP-1 $(10 \mu \mathrm{M})$ after addition of each metal ions (20 eq), amino acid (20 eq), and lysozyme $\left(1-100 \mu \mathrm{g} / \mathrm{mL}\right.$ ) in ethanol-water solution (EtOH:DI $\left.\mathrm{H}_{2} \mathrm{O}=4: 6, v / v\right)$, measured after $1 \mathrm{~min}$ at $25^{\circ} \mathrm{C}$. (A) FeP-1, (B) $\mathrm{FeCl}_{3}$, (C) $\mathrm{FeCl}_{2}$, (c) $\mathrm{FeCl}_{2}+\mathrm{FeCl}_{3}$, (D) $\mathrm{Hg}\left(\mathrm{NO}_{3}\right)_{2}$, (d) $\mathrm{Hg}\left(\mathrm{NO}_{3}\right)_{2}+\mathrm{FeCl}_{3}$, (E) $\mathrm{AgCl}$, (e) $\mathrm{AgCl}+\mathrm{FeCl}_{3}$, (F) $\mathrm{CdCl}_{2}$, (f) $\mathrm{CdCl}_{2}+\mathrm{FeCl}_{3},(\mathrm{G}) \mathrm{NiCl}_{2}$, (g) $\mathrm{NiCl}_{2}+\mathrm{FeCl}_{3}$, (H) $\mathrm{CuCl}_{2}$, (h) $\mathrm{CuCl}_{2}+\mathrm{FeCl}_{3}$, (I) $\mathrm{PdCl}_{2}$, (i) $\mathrm{PdCl}_{2}+\mathrm{FeCl}_{3}$, (J) $\mathrm{ZnCl}_{2}$, (j) $\mathrm{ZnCl}_{2}+\mathrm{FeCl}_{3}$, (K) $\left(\mathrm{C}_{2} \mathrm{H}_{5}\right)_{3} \mathrm{PAuCl}$, (k) $\left(\mathrm{C}_{2} \mathrm{H}_{5}\right)_{3} \mathrm{PAuCl}+\mathrm{FeCl}_{3}$, (L) $\mathrm{KCl}$, (l) $\mathrm{KCl}+\mathrm{FeCl}_{3}$, (M) $\mathrm{CaCl}_{2}$, (m) $\mathrm{CaCl}_{2}+\mathrm{FeCl}_{3}$, (N) $\mathrm{NaCl}$, (n) $\mathrm{NaCl}+\mathrm{FeCl}_{3}$, (O) $\mathrm{MgCl}_{2}$, (o) $\mathrm{MgCl}_{2}+\mathrm{FeCl}_{3},(\mathrm{P})$ L-Cysteine, (p) L-Cysteine $+\mathrm{FeCl}_{3}$, (Q) L-Glutamine, (q) L-Glutamine $+\mathrm{FeCl}_{3},(\mathrm{R})$ L-Lysine, (r) L-Lysine $+\mathrm{FeCl}_{3}$, (S) Lysozyme $1 \mu \mathrm{g} / \mathrm{mL}$, (s) Lysozyme $1 \mu \mathrm{g} / \mathrm{mL}+\mathrm{FeCl}_{3}$, (T) Lysozyme $10 \mu \mathrm{g} / \mathrm{mL}$, (t) Lysozyme $10 \mu \mathrm{g} / \mathrm{mL}+\mathrm{FeCl}_{3}$, (U) Lysozyme $100 \mu \mathrm{g} / \mathrm{mL}$, (u) Lysozyme $100 \mu \mathrm{g} / \mathrm{mL}+$ $\mathrm{FeCl}_{3}$. Means and standard deviations calculated from multiple measurements $(n=5)$. Dotted-line: $\mathrm{Fe}(\mathrm{III})$-responsive signal threshold (at 32 a.u.). The emission spectrum was measured under excitation at $397 \mathrm{~nm}$.

Next, a selectivity of FeP-1 toward Fe(III) not Fe(II) was double-checked by simply introducing oxidizing agent; $\mathrm{Fe}(\mathrm{II})$ to $\mathrm{Fe}(\mathrm{III})$. Significant fluorescence enhancement began to be observed after adding the oxidizing agent $\left(\mathrm{H}_{2} \mathrm{O}_{2}\right.$ in this study) into the solution of FeP-1 and Fe(II) (Figure S6). The optimal range for the fluorescence sensing of $\mathrm{Fe}(\mathrm{III})$ with FeP-1 was found to be $\mathrm{pH}$ 4-8 including physiological $\mathrm{pH}$ (Figure S7). Additionally, no significant counter anion effect was confirmed by comparing the fluorescence signal response of FeP-1 toward $\mathrm{FeCl}_{3}$ and $\mathrm{Fe}\left(\mathrm{NO}_{3}\right)_{3}$, respectively (Figure S8).

The optimized molecular structures and HOMO-LUMO energy levels of FeP-1 as well as FeP-1 + Fe(III) complex were obtained by computational calculations (Figure 2a). In the FeP-1 calculation, the intramolecular hydrogen bonding (H-bonding) between hydroxyl proton on the naphthalene backbone and imine was clearly observed in the Schiff ligand pocket, that can cause ESIPT-induced fluorescence quenching [16]. The localized electron distribution on the amine donor in HOMO, which is shifted to the imine moiety in LUMO, indicated the intramolecular charge transfer (ICT) character of D-A type fluorophores [18]. In contrast to FeP-1, FeP-1 + Fe(III) complex showed that 
$\mathrm{Fe}(\mathrm{III})$ coordinates with Schiff base ligand; hydroxy, imine, and thiomethyl, with missing of H-bonding between naphthol and imine. In the side view of the FeP-1 + Fe(III) complex, the thiomethyl-aniline showed a tilted conformation at an angle of $146^{\circ}$, from the naphthalene backbone to make a coordinate with $\mathrm{Fe}(\mathrm{III})$ (Figure 2b).

(a)

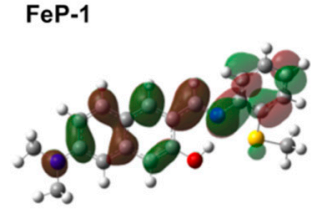

$\operatorname{LUMO}(-2.08 \mathrm{eV})$

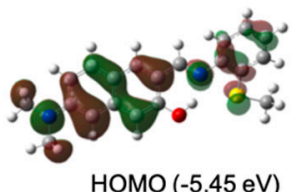

$\mathrm{FeP}-1+\mathrm{Fe}(\mathrm{III})$

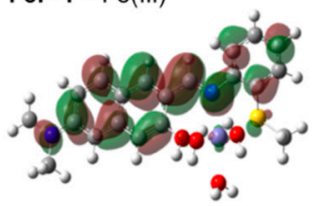

LUMO (-3.05 eV)

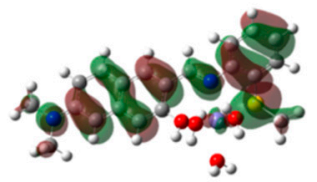

HOMO $(-7.07 \mathrm{eV})$ (b) Plane view

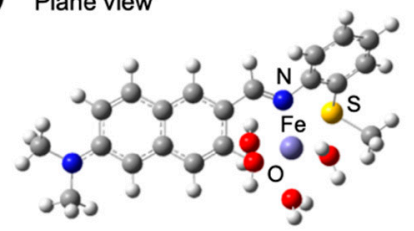

Side view

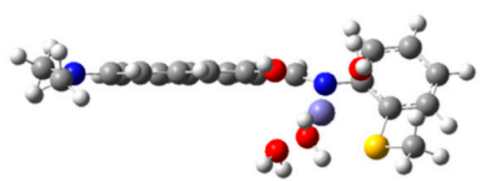

Figure 2. (a) The optimized molecular structures and HOMO/LUMO, and energy levels of FeP-1, FeP-1 + Fe(III) complex by DFT calculations (APFD/6-31+G(d,p)). (b) Plane/side view of FeP-1 + Fe(III) complex. Fe(III) complex contains three additional water molecules in DFT calculations.

Before moving on to the bioimaging application, we verified the imine stability of FeP-1 and its Fe(III) complex. Generally, an imine moiety could be hydrolyzed under acidic conditions or metal-coordination. To verify this factor, we conducted ${ }^{1} \mathrm{H}$ NMR comparison for FeP-1 and its incubation product with $\mathrm{Fe}(\mathrm{III})$. New peaks were not observed in this study, which indicates the stability of imine-moiety and fluorescence enhancement derived from the Fe(III) coordination, not hydrolysis (Figure S9). The imine stability of FeP-1 was also tested in the sensing solution and cell lysate solution (whole cell lysate, HeLa cell, number of cells: $\left.5 \times 10^{5}\right)$ in cell culture media $(10 \%$ fetal bovine serum and $1 \%$ penicillin-streptomycin, w/o phenol red) at different temperatures $\left(25^{\circ} \mathrm{C}, 37^{\circ} \mathrm{C}\right)$ during 60 min incubations. The stability of FeP-1 was followed by change of absorption spectrum and intensity. In this test, we observed: (i) No changes in sensing solution, (ii) slightly increased intensity of FeP-1 after $60 \mathrm{~min}$ incubation in the cell lysate solution without peak shift, which is correlated with intensity increment of FeP-1 after binding of intracellular Fe(III). These data indicate sufficient stability of FeP-1 in the sensing condition as well as cellular environment (Figure S10).

Next, FeP-1 was applied to the bioimaging of Fe(III) in the cancer cell line, HeLa (immortalized human cervical cancer cell). When HeLa cells were incubated with FeP-1, a moderate fluorescence signal was observed in the cytosol within the yellow channel of confocal laser scanning microscopy (CLSM) (Figure 3a,b). When the exogenous source of $\mathrm{Fe}(\mathrm{III})\left(\mathrm{FeCl}_{3}, 50 \mu \mathrm{M}\right)$ was post-incubated, the yellow emission was much brighter than that of the control group treated with FeP-1. The relative emission images in the experimental sets indicate that the selective sensing ability of FeP-1 on Fe(III) in biological condition. The autofluorescence from the intrinsic fluorophores in the cells was not observed in the experiment condition (see control set in Figure 3a). In addition, FeP-1 (0-100 $\mu$ M) showed low cytotoxicity $(<10 \%)$ in the cell viability assay, which holds great potential for further applications in bio-imaging as well as in biological mechanism studies (Figure 3c). 
(a)
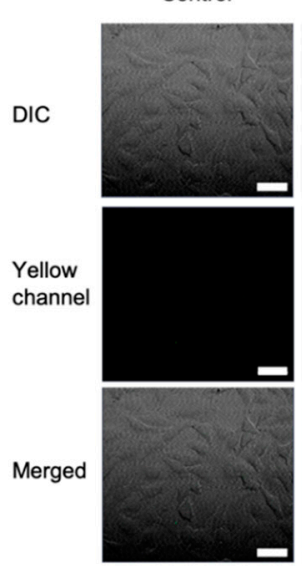

FeP-1
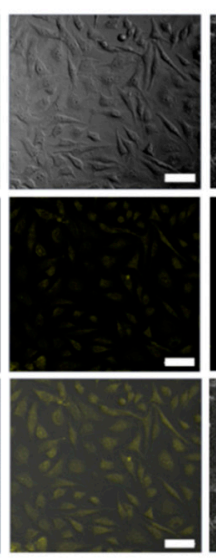

$\mathrm{Fe}$ (III)

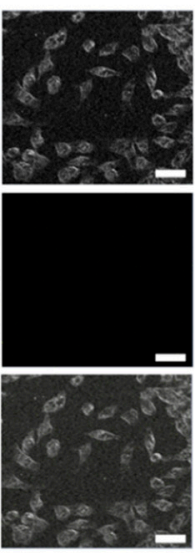

$\mathrm{FeP}-1+\mathrm{Fe}(\mathrm{III})$

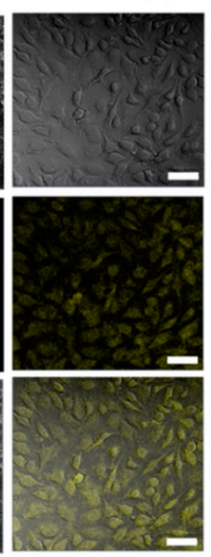

(b)

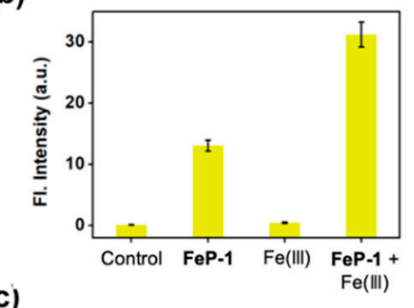

(c)

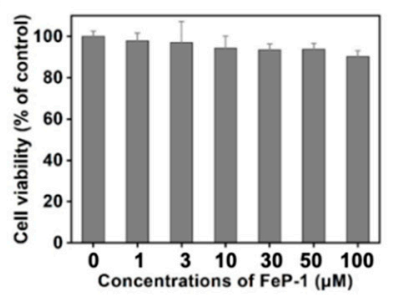

Figure 3. (a) CLSM images of the FeP-1 $(50 \mu \mathrm{M})$ in HeLa cells (magnification, $\times 20)$. Control: cells only; FeP-1: cells with the FeP-1 $(50 \mu \mathrm{M})$ incubated for $2 \mathrm{~h}$; Fe(III): cells with the Fe(III) $(50 \mu \mathrm{M})$ incubated for $2 \mathrm{~h}$; FeP-1 + Fe(III): cells pretreated the FeP-1 $(50 \mu \mathrm{M})$ for $2 \mathrm{~h}$ and then incubated with $\mathrm{FeCl}_{3}(50 \mu \mathrm{M})$ for $2 \mathrm{~h}$. Excitation wavelengths $450 \mathrm{~nm}$, and detection wavelengths channel were $455-600 \mathrm{~nm}$, respectively. Scale bar is $20 \mu \mathrm{m}$. DIC: bright field, Yellow channel: fluorescence detection channel (455-600 nm), Merged: superimposed image of DIC and yellow channel. (b) The relative fluorescence intensity shown in panel (a). (c) Cell viability of FeP-1. Cells were incubated with $0-100 \mu \mathrm{M}$ of FeP-1 for $24 \mathrm{~h}$ in HeLa cells.

\section{Conclusions}

In summary, we have shown that a Schiff base fluorescent probe senses Fe(III). The probe shows a fluorescence enhancement at $550 \mathrm{~nm}$ upon addition of $\mathrm{Fe}(\mathrm{III})$, owing to a decrement of the ESIPT induced quenching effect. The introduction of the ESIPT approach into the Schiff base moiety of naphthalene-based D-A type fluorescent platform is new, and has a chance to develop into a more advanced system. Although the probe showed limitations such as sensing of Fe(III) in the mixture of organic solvents and interference from some metal ions, the probe showed high sensitivity with fast fluorescence response times with $\mathrm{Fe}(\mathrm{III})$. The application of probes for Fe(III) sensing in the cancer cell were successfully carried out. In this paper, we exclusively present a new Schiff ligand for Fe(III), which we believe it has the capability to serve as a practical sensor for Fe(III) detection in biomedical applications.

Supplementary Materials: The following are available online at http://www.mdpi.com/1424-8220/19/11/2500/s1, Supplementary Figures: summary of known fluorescent probes, UV/Vis absorption and fluorescence spectra, ESIPT pathway, NMR analysis, HR-mass spectra.

Author Contributions: N.H.K. performed the synthesis, characterization, and sensing study. J.L. and S.P. performed the quantum chemical calculation. J.J. performed bio-related study. D.K. conceived the project, analyzed the data and wrote the manuscript with J.J.

Funding: This research was supported by the Bio \& Medical Technology Development Program of the National Research Foundation (NRF) of Korea funded by the Ministry of Science \& ICT (NRF-2018-M3A9H3021707) and Basic Science Research Program through the National Research Foundation (NRF) of Korea funded by the ministry of Education (NRF-2018R1A6A1A03025124, NRF-2018R1D1A1B07043383).

Acknowledgments: Thanks to Neil P. George and Sujin Jung for the linguistic editing.

Conflicts of Interest: The authors declare no conflict of interest.

\section{References}

1. Guo, Z.; Park, S.; Yoon, J.; Shin, I. Recent progress in the development of near-infrared fluorescent probes for bioimaging applications. Chem. Soc. Rev. 2014, 43, 16-29. [CrossRef] [PubMed] 
2. Tang, Y.; Lee, D.; Wang, J.; Li, G.; Yu, J.; Lin, W.; Yoon, J. Development of fluorescent probes based on protection-deprotection of the key functional groups for biological imaging. Chem. Soc. Rev. 2015, 44, 5003-5015. [CrossRef] [PubMed]

3. Yin, J.; Hu, Y.; Yoon, J. Fluorescent probes and bioimaging: Alkali metals, alkaline earth metals and $\mathrm{pH}$. Chem. Soc. Rev. 2015, 44, 4619-4644. [CrossRef] [PubMed]

4. Abbaspour, N.; Hurrell, R.; Kelishadi, R. Review on iron and its importance for human health. J. Res. Med. Sci. 2014, 19, 164-174. [PubMed]

5. Muckenthaler, M.U.; Rivella, S.; Hentze, M.W.; Galy, B. A Red Carpet for Iron Metabolism. Cell 2017, 168, 344-361. [CrossRef] [PubMed]

6. Hadzhieva, M.; Kirches, E.; Mawrin, C. Review: Iron metabolism and the role of iron in neurodegenerative disorders. Neuropathol. Appl. Neurobiol. 2014, 40, 240-257. [CrossRef] [PubMed]

7. Zumbrennen-Bullough, K.; Babitt, J.L. The iron cycle in chronic kidney disease (CKD): From genetics and experimental models to CKD patients. Nephrol. Dial. Transplant 2014, 29, 263-273. [CrossRef] [PubMed]

8. Abbate, V.; Hider, R. Iron in biology. Metallomics 2017, 9, 1467-1469. [CrossRef] [PubMed]

9. Sahoo, S.K.; Sharma, D.; Bera, R.K.; Crisponi, G.; Callan, J.F. Iron(iii) selective molecular and supramolecular fluorescent probes. Chem. Soc. Rev. 2012, 41, 7195-7227. [CrossRef] [PubMed]

10. Wu, J.; Liu, W.; Ge, J.; Zhang, H.; Wang, P. New sensing mechanisms for design of fluorescent chemosensors emerging in recent years. Chem. Soc. Rev. 2011, 40, 3483-3495. [CrossRef] [PubMed]

11. Kim, D.; Moon, H.; Baik, S.H.; Singha, S.; Jun, Y.W.; Wang, T.; Kim, K.H.; Park, B.S.; Jung, J.; Mook-Jung, I.; et al. Two-Photon Absorbing Dyes with Minimal Autofluorescence in Tissue Imaging: Application to in Vivo Imaging of Amyloid- $\beta$ Plaques with a Negligible Background Signal. J. Am. Chem. Soc. 2015, 137, 6781-6789. [CrossRef] [PubMed]

12. Kim, D.; Baik, S.H.; Kang, S.; Cho, S.W.; Bae, J.; Cha, M.-Y.; Sailor, M.J.; Mook-Jung, I.; Ahn, K.H. Close Correlation of Monoamine Oxidase Activity with Progress of Alzheimer's Disease in Mice, Observed by in Vivo Two-Photon Imaging. ACS Cent. Sci. 2016, 2, 967-975. [CrossRef] [PubMed]

13. Jung, Y.; Ju, I.G.; Choe, Y.H.; Kim, Y.; Park, S.; Hyun, Y.-M.; Oh, M.S.; Kim, D. Hydrazine Exposé: The Next-Generation Fluorescent Probe. ACS Sens. 2019, 4, 441-449. [CrossRef] [PubMed]

14. Jung, Y.; Kim, Y.; Kim, N.H.; Lee, J.; Kim, K.-H.; Jung, J.; Huh, Y.; Jang, H.-J.; Joo, J.; Park, S.; et al. A wavelength-tunable and facilely functionable D-A type naphthalene core skeleton: Synthesis, photophysical property, and bio-imaging applications for cells and tissues. Dyes Pig. 2019, 162, 104-111. [CrossRef]

15. Sedgwick, A.C.; Wu, L.; Han, H.-H.; Bull, S.D.; He, X.-P.; James, T.D.; Sessler, J.L.; Tang, B.Z.; Tian, H.; Yoon, J. Excited-state intramolecular proton-transfer (ESIPT) based fluorescence sensors and imaging agents. Chem. Soc. Rev. 2018, 47, 8842-8880. [CrossRef]

16. Yin, H.; Li, H.; Xia, G.; Ruan, C.; Shi, Y.; Wang, H.; Jin, M.; Ding, D. A novel non-fluorescent excited state intramolecular proton transfer phenomenon induced by intramolecular hydrogen bonds: An experimental and theoretical investigation. Sci. Rep. 2016, 6, 19774. [CrossRef]

17. Kim, S.; Seo, J.; Park, S.Y. Torsion-induced fluorescence quenching in excited-state intramolecular proton transfer (ESIPT) dyes. J. Photochem. Photobiol. A Chem. 2007, 191, 19-24. [CrossRef]

18. Singha, S.; Kim, D.; Roy, B.; Sambasivan, S.; Moon, H.; Rao, A.S.; Kim, J.Y.; Joo, T.; Park, J.W.; Rhee, Y.M.; et al. A structural remedy toward bright dipolar fluorophores in aqueous media. Chem. Sci. 2015, 6, 4335-4342. [CrossRef] [PubMed]

(C) 2019 by the authors. Licensee MDPI, Basel, Switzerland. This article is an open access article distributed under the terms and conditions of the Creative Commons Attribution (CC BY) license (http://creativecommons.org/licenses/by/4.0/). 